\title{
Research on Early Warning and Intervention Mechanism of College Students' Psychological Crisis Based on Social Support
}

\author{
Qifeng Zhang, Songyang Wang \\ School of Foreign Languages, Hangzhou Dianzi Univerity, Hangzhou 310018, Zhejiang, China
}

\begin{abstract}
Aimed at the causes and specific manifestations of college students' psychological crisis, an early warning and intervention mechanism combined with the theory of social support was proposed for college students' psychological crisis. Particularly, from the perspectives of school partners, teachers, relatives and friends, and schools, we proposed support measures for college students in psychological crisis, so as to create a healthy and active learning and living environment, in order to promote college students' mental health, and to cultivate a qualified builder with a comprehensive combination of morality, intelligence, physical education, art and labor.
\end{abstract}

Keywords: Social support, Psychological crisis of college students, Early warning, Intervention.

\section{Introduction}

At present, college students are facing more diverse challenges, as social forms and values are becoming more and more diversified, especially the pace of life in cities gradually accelerating; With distress and pressure, psychological problems and psychological crises are becoming more common. According to the statistics of Dr. Hu Yue from Dalian University of Technology, 26\% of college students in our country have suicidal ideation, and suicide has become the first cause of death for young people aged 15-34 in our country. How to carry out early warning and intervention of college students' psychological crisis is an important task facing colleges and universities. It is of greater significance for promoting the healthy and happy growth of college students and maintaining campus safety and stability.

\section{The Connotation of Social Support Theory}

As an important support system for individuals, social support mainly refers to the general or specific support resources that individuals obtain from social network. Such resources can help individuals improve their social adaptation and protect individuals from adverse environmental impacts and harms[1]. Based on the systematic analysis of the early warning and intervention mechanisms for college students' psychological crisis established by various universities, this article analyzes the need to rebuild confidence in life from the perspective of college students having had psychological crises, and judges what kind of support college students need to eradicate psychological, environmental and practical disadvantages. From the perspective of the internal generation mechanism, college students in psychological crisis need help and support from schools, teachers, school partners, families, hospitals, and all walks of life. In particular, they need to create a positive, healthy and warm learning and living atmosphere for them to promote their importance. Pick up confidence and get out of the predicament. From the perspective of external generation mechanism, conduct research from various aspects such as the social environment system, university education leading system, school system guarantee system, campus culture construction system and family education system, and discuss strengthening early warning and timely intervention of college students' psychological crises. It not only helps students with psychological problems get out of the predicament, but also plays an important driving force to promote a more healthy and orderly development of the social environment, college education environment and family living environment.

\section{The Main Forms of Students with Psychological Crisis}

The classification of psychological crisis of college students is generally divided into three situations: developmental crisis, situational crisis and existential crisis[2]. They often exhibit relatively strong emotional fluctuations, with major changes in their body, behavior, and cognition, and are even unable to carry out policy learning and life. It requires classmates, teachers, parents, logistics guards, doctors, and the smart campus system to be keenly aware of students' abnormal psychology and behavior, distinguish and identify crisis targets, and issue early warning information in a timely manner, and counselors and leaders to evaluate the early warning information based on the early warning indicators, identify the targets of intervention, make early predictions of possible dangers, and take precautions before they happen. It needs to focus on students who have mental illness and other related problems found in mental health assessments or consultation conversations conducted by the University Mental Health Center, students who have psychological problems caused by unexpected stimulation due to family problems, emotional problems, economic problems, etc. or due to academic pressures such as graduation, final exams, postgraduate entrance examinations, etc., students who are introverted, self-closed, and have little communication with family and classmates, having obvious depression tendency, students who have serious mental illnesses before entering the university, especially those who take long-term mental health problem drugs and students who are exposed to originally poor family environment and long-term lack of social support. 


\section{Research on the Construction of the Early Warning Mechanism of College Students' Psychological Crisis from the Perspective of Social Support}

Psychological crisis has the characteristics of "the coexistence of development and existence, potentiality and suddenness, harm and opportunity"[3]. When designing and improving the psychological crisis early warning system for college students, we should pay attention to the characteristics of individual psychological crisis college students and the active role of individuals and the Internet system to stimulate the enthusiasm of teachers and students for mutual assistance.

\subsection{Early Warning of Fellow Students}

The scope of school companions includes roommates, classmates, class committees and other student leaders, student party members, etc. School companions are the most frequent people in daily contact with psychological crisis college students, and they are also the people who can find problems in a timely manner. In daily study, work and life with college students having psychological problems, they can grasp each other's psychological conditions in time, and sometimes they can be discovered in time in the early stages of psychological problems. If they find that there are mental problems among your classmates and the situation is relatively minor, you can provide positive guidance through conversations and other methods to help him reduce the pressure; for the more serious situation where the performance of the mental problem has completely exceeded the student's own ability to handle, it is necessary to report to the school psychology center or the counselor of the department at the first time.

\subsection{Early Warning of Faculty}

The faculty includes counselors, head teachers, class teachers, school hospital doctors, and logistics security personnel. In the process of question and answer and communication between teachers and students, the daily heart-to-heart talks and dormitory visits between the counselor and the head teacher, the doctors in the school hospital and the staff of the psychological counseling center interviewed and talked, and the guards patrolling and daily work, if the abnormal performance of college students is discovered, timely evaluation should be carried out, and timely feedback should be given to the department or psychology center of the college, so as to be able to intervene in time for the students who have problems.

\subsection{Early Warning of Relative and Friend}

Relatives and friends include parents, relatives and friends. Parents find problems in their family life during the holiday and their usual phone calls and videos. Relatives and friends, especially boy and girl friends who have established a relationship, have frequent daily life and communication, and the probability of finding problems is the greatest. After discovering the abnormal behavior of college students, on the one hand, relatives and friends should promptly reassure them. On the other hand, communicate effectively with the school and parents on the other hand in order to take timely actions to intervene.

\subsection{Early Warning of Smart Campus System}

The smart campus system includes dormitory, library, laboratory access control system, 110 alarm system, catering credit card system, campus camera monitoring system, etc. For example, the staff of the campus monitoring system found that some college students were sitting in one place for a long time late at night or staying on the roof terrace for a long time without returning to the dormitory; the dormitory access control system showed that some college students had not returned for a few days on non-holidays; the campus attendance system found that the students did not go to class for a few days; students' final exam scores this semester dropped sharply compared with the previous semester, and they even failed many courses and other abnormal performances. These issues require timely attention from campus workers, and timely intervention on the basis of timely analysis of big data.

\section{Research on the Construction of the Intervention Mechanism of College Students' Psychological Crisis from the Perspective of Social Support}

\subsection{Support of Fellow Students}

School companions are the group with which college students have the closest relationship in the college environment. They usually study together and live together after class. They are independent and support each other. Because of equal individual status, they are easier to get along with, have a common living environment and hobbies, and it is easy to form an intimate relationship. They are the most important source of support for college students during their studies, and they have an important influence on the formation of their outlook on life, world outlook and values. When encountering psychological problems, college students are the easiest to communicate with their classmates and pass on their true thoughts to them. Although some students will not report their problems to their classmates, many abnormal behaviors will be easier for classmates to discover. Classmates who find problems inform the teacher in time, and if effective measures are taken, the loneliness of college students in psychological crisis can be reduced, and they feel that they are still accepted and not easy to go to extremes. Therefore, creating a warm class and dormitory environment, actively playing the positive role of class cadres and dormitory students, caring for and supporting each other, will reduce the occurrence of psychological crisis behaviors of college students. And even if psychological crisis behaviors occur, it may reduce the consequences of such behaviors.

\subsection{Support of Faculty}

Teachers include counselors, class teachers and psychology teachers. Counselors are the teachers most contacted by college students. Many college counselors regard promoting the mental health of college students as the main task of their work. Excellent counselors are often trusted by college 
students. Students are willing to communicate frankly with counselors, hoping to obtain positive guidance and spiritual support from the teachers. There are many things that college students do not want to be known by other students. The counselors actively help students with psychological problems and provide them with spiritual support while doing it confidentiality. Especially in the case of a psychological crisis, counselors with a certain degree of psychological knowledge can promptly handle the crisis in accordance with the school's psychological crisis plan, which can reduce the loss caused by the crisis. Class teachers are the main body of classroom teaching, and students often find abnormalities in classroom communication. On the one hand, they should carry out emergency response in a timely manner, and on the other hand, they give feedback to the instructors and other academic management personnel. In many cases, class teachers are recognized by students for their professionalism, which often makes students hope to have a spiritual exchange with class teachers. Teachers' positive feedback and active guidance sometimes play a key role, providing greater internal support for college students when sudden psychological problems arise. Psychological teachers are experts in psychological problems in schools. On the one hand, it provides psychological counseling for all students in the school, and on the other hand, it provides psychological business guidance for student workers. For special professional mental illnesses, it is necessary for psychological teachers or joint psychologists to take measures to effectively intervene students in sudden psychological crisis in a timely manner to reduce the harm of mental illness to students.

\subsection{Support of Relative and Friend}

Parents are important to college students. A good family environment is an important support for college students to grow into talents. On the contrary, the bad family environment is often an important reason for the psychological problems of college students. Especially when college students have psychological problems, the absence of parental care often aggravates the psychological problems. Although different families are happy or not for different reasons, when it is discovered that a child has a mental illness, especially when a sudden psychological crisis occurs, parents should lower their attitude and use a more peaceful language and an equal attitude to care and love. And in later life, they try to create a relatively good family environment in order to provide strong psychological support for the children. Grandparents are important relatives of college students, and they often say that they are separated from each other. Many families are absent from caring for their children due to various reasons such as the work of their parents, but grandparents often have the effect of replacing them. For college students with psychological problems, there are some families whose grandparents can even become the spiritual pillar of their children. Brothers and sisters and other relatives and friends, especially relatives and friends of the same generation are more equal in relationship with college students in psychological crisis. There is no generation gap, and therefore the care and support they often give is more acceptable to the parties. Therefore, listening, counseling, and sometimes simple material support among the peers can alleviate the occurrence of psychological problems, and sometimes even when there is a sudden psychological crisis, it will be of great help.

\subsection{Support of School}

From the perspective of the school, one is to establish a special leadership agency for dealing with psychological problems of college students, set up a system for early warning and intervention of college students' psychological crises, and formulate response plans after the emergence of psychological crises. The second is to conduct special training on the care and emergency handling of psychological crisis college students for all workers related to student work in the whole school, so that teachers can understand how to deal with problems in a timely manner, and give the students emotional and material attention as much as possible during the whole process of the university. The support of the school creates an optimistic and positive campus cultural atmosphere in the whole school. The third is to provide different policy support for different student groups. For example, for college students who have psychological problems due to financial difficulties, the school should improve the scholarship and grant system on the one hand, and on the other hand, ask relevant counselors to focus on the parties concerned and guide them to establish correct values. The school should also give them a preference when they are involved in work-study positions, and when they encounter various special circumstances such as natural disasters, they should be given temporary hardship subsidies to help them tide over the difficulties. For college students who have a psychological crisis due to excessive learning pressure, the school can relieve them by helping them change majors or offering academic assistance.

\section{Conclusion}

The construction of early warning and intervention mechanisms for college students' psychological crises requires the collaboration of schools, families, and society at all levels. As a group of college students, students, teachers, relatives and friends should pay more attention to the people around them in their daily study, life and work, and give each other more support and company, so as to create more positive, healthier and relatively relaxed college students. The environment of psychological adaptation promotes the healthy and happy growth of college students.

\section{Acknowledgement}

This work was supported by the Research Project of Zhejiang Higher Education Association in 2021: Research on the Psychological Crisis Management Mechanism of College Students Based on Social Support (KT2021074).

\section{References}

[1] Luo Jie, Liu Zhenhui, Zhang Jinzhong, etc. The impact of social support on college freshmen's admission adaptation: analysis of multiple mediating effects $[\mathrm{J}]$. Journal of Guizhou Normal University (Natural Science Edition), 2020, (6): 101-106. 
[2] Zeng Qingdi. Review of research on psychological crisis intervention for college students [J]. Ideological and Theoretical Education, 2006, (12): 52-55.

[3] Jiang Tusheng, Deng Zhuoming. Analysis of the types of college students' psychological crisis [J]. Contemporary Youth Research, 2013 (2).98-103. 